\title{
QUALIDADE MICROBIOLÓGICA DE LEITE EM FUNÇÃO DE TÉCNICAS PROFILÁTICAS NO MANEJO DE PRODUÇÃO
}

\author{
Microbiological quality of milk through preventive techniques in the handling of production
}

\author{
Paola Kiara Guerreiro ${ }^{1}$, Márcia Regina Fragoso Machado ${ }^{1}$, Gilberto Costa Braga ${ }^{2}$, \\ Eliane Gasparino $^{3}$, Alexandra da Silva Martinez Franzener ${ }^{1}$
}

\begin{abstract}
RESUMO
A indústria leiteira atravessa um período de intensas transformações em sua estrutura, e a qualidade do leite é uma das principais exigências. A correta adoção de medidas de higiene adequadas na produção, armazenamento e transporte do leite podem prevenir a contaminação de microrganismos psicrotróficos que representam um grave problema econômico para a indústria de laticínios. Desta forma, este estudo realizou-se com o objetivo de avaliar o efeito de diferentes técnicas profiláticas de higiene e limpeza, durante o manejo de produção, na qualidade microbiológica de leite através da contagem de bactérias psicrotróficas. As técnicas profiláticas foram avaliadas envolvendo quatro propriedades produtoras de leite. Tais técnicas foram testadas antes, durante e após a ordenha para a adoção de práticas de higiene e limpeza de utensílios e equipamentos, dos operadores/ordenhadores, do ambiente de ordenha e do manejo dos animais. Em cada propriedade foi coletada uma amostra controle, antes da adoção das profilaxias, e posteriormente amostras periódicas de quatro ordenhas. Com base no questionário aplicado, constatou-se que em todas as propriedades havia falhas nos procedimentos de higiene e limpeza e ocorrência de muitos animais com mastite sub-clínica. Concluiu-se que após a adoção das técnicas de profilaxias, ocorreram diminuições significativas na contagem de bactérias psicrotróficas do leite em todas as propriedades rurais estudadas, comprovando a importância das práticas preventivas de higiene e limpeza sobre a qualidade microbiológica do leite.
\end{abstract}

Termos para indexação: Qualidade do leite; bactérias psicrotróficas; profilaxia.

\begin{abstract}
The milk industry lives a time of strong transformations in your structure, and the quality of the milk is one of the most important demands. The correct adoption of appropriate hygiene measures in the production, storage and transport of the milk can prevent the contamination of psichrotrofics microorganisms that represents a serious economical problem for the industry of dairy products. This study was carried out with the objective of evaluating the effect of the adoption of different preventive techniques of hygiene and cleaning, during the production handling, in the microbiological quality of milk measured for the count of psichrotrofics bacteria. The preventive techniques were appraised involving four farms milk producers. Such techniques were tested before, during and after the milk round to get being hygiene practices and cleaning of: utensils and equipments; operators / milks-man; environment of milk round; and handling of the animals. In each farm a sample was collected for control, before the adoption of the prophylaxes, and later four periodic samples were collected. Based in the applied questionnaire, it could be verified that happened flaws in the hygiene and cleaning procedures in all the farms and a lot of cows was diseased with sub-clinic infection. It was conclude that after the adoption of the techniques of prophylaxes all the farms shown significant decreases in the count of psichrotrofics bacteria, proving the importance of the hygiene and cleaning preventive practices on the milk microbiological quality.
\end{abstract}

Index terms: Milk quality; psichrotrofics bacteria; prophylaxes.

(Recebido para publicação em 11 de setembro de 2003 e aprovado em 11 de janeiro de 2005)

\section{INTRODUÇÃO}

O leite, por natureza, é um alimento rico em nutrientes contendo proteínas, carboidratos, gorduras, vitaminas e sais minerais. Sua qualidade é um dos temas mais discutidos atualmente dentro do cenário nacional de produção leiteira. Depois de secretado no do úbere, o leite pode ser contaminado por microrganismos a partir de três principais fontes: de dentro da glândula mamária, da su- perfície exterior do úbere e tetos, e da superfície do equipamento e utensílios de ordenha e tanque (SANTOS e FONSECA, 2001). Desta forma, a saúde da glândula mamária, a higiene de ordenha, o ambiente em que a vaca fica alojada e os procedimentos de limpeza do equipamento de ordenha são fatores que afetam diretamente a contaminação microbiana do leite cru.

Adicionalmente, são igualmente importantes a temperatura e o período de tempo de armazenagem do lei-

1. Alunas de Graduação do Curso de Zootecnia - CCA / UNIOESTE - Campus de Marechal Cândido Rondon, PR - fragosom@bol.com.br; pakigue@hotmail.com

2. Professor, Dr. do Curso de Agronomia - CCA / UNIOESTE - Campus de Marechal Cândido Rondon, PR - gbraga@unioeste.br

3. Professora, Dra do Curso de Zootecnia - CCA / UEM - Maringá, PR - egasparino@uem.br 
te, uma vez que estes dois fatores estão diretamente ligados com a multiplicação dos microrganismos presentes no leite, afetando, conseqüentemente, a contagem bacteriana total (FONSECA, 1998).

A importância dos microrganismos do leite revela que o conhecimento sobre o seu índice de contaminação microbiana pode ser usado no julgamento de sua qualidade intrínseca, bem como das condições sanitárias de sua produção e da saúde do rebanho. Considerando o potencial de se multiplicarem, as bactérias do leite podem causar alterações químicas, tais como a degradação de gorduras, de proteínas ou de carboidratos, podendo tornar o produto impróprio para o consumo e industrialização (COUSIN, 1982).

Mesmo sob refrigeração o leite pode ser facilmente deteriorado, servindo para a proliferação de grande número de bactérias. Algumas bactérias conseguem dobrar sua população a cada 20 a 30 minutos e, por isso, o leite deve ser manuseado corretamente desde o momento da ordenha até chegar à indústria de laticínios e ao consumidor final.

A qualidade do produto final esta diretamente relacionada à carga microbiológica do leite ao chegar na indústria beneficiadora. A aceitação do leite fluido por parte do consumidor depende em grande parte das suas características sensoriais, tais como sabor e aroma, assim como do seu valor nutricional, atributos esses que podem ser alterados pela ação proteolítica e lipolítica de bactérias psicrotróficas, com prejuízos ao tempo de vida-de-prateleira e à qualidade do leite pasteurizado (MA et al., 2000).

Devido ao amplo uso da refrigeração do leite na fazenda, a atividade lipolítica de origem microbiana ocorre, principalmente, devido às bactérias psicrotróficas, as quais são as predominantes no leite refrigerado. As lipases secretadas por estes microrganismos Gramnegativos são hidrolases que atuam principalmente na posição $\alpha$ dos triglicerídeos (CASTBERG, 1992). Normalmente, se as condições higiênicas de produção e armazenamento do leite forem satisfatórias, as lipases bacterianas não apresentarão impacto importante sobre a lipólise do leite antes da pasteurização. No entanto, devido a característica destas enzimas de sobreviverem à pasteurização, a sua atividade lipolítica passa a ser importante, principalmente quando a contagem de psicrotróficos ultrapassa $10^{6} / 10^{7}$ ufc/ml (DOWNEY, 1980).

De outra forma, a qualidade do leite cru é influenciada por múltiplos fatores, entre os quais destacamse os zootécnicos, associados ao manejo, saúde da glândula mamária, alimentação e potencial genético dos rebanhos, e outros fatores relacionados à obtenção e armazenagem do leite recém-ordenhado. Os parâmetros físico-químicos, microbiológicos e higiênicos sanitários são utilizados pelas indústrias para verificar e determinar a qualidade do leite, como por exemplo, a contagem de células somáticas, a contagem de microrganismos psicrotróficos e resíduos de antibióticos que estão sendo cada vez mais exigidos como parâmetros de qualidade (SANTOS e FONSECA, 2001).

Fontes ambientais de contaminação do leite incluem a água utilizada na limpeza do equipamento e em outras tarefas. É de fundamental importância que a água usada para estes fins seja potável, com baixa contaminação por coliformes e outros gêneros bacterianos como Pseudomonas e Bacillus (COUSIN e BRAMLEY, 1981). O leite pode ser contaminado quando entra em contato com a superfície do equipamento e/ou utensílios de ordenha, assim como no próprio tanque de refrigeração do leite. A contagem bacteriana total do leite pode aumentar significativamente quando em contato com equipamentos nos quais a limpeza e sanitização são deficientes, pois os microrganismos proliferam nos resíduos de leite presentes em recipientes, borrachas, junções e qualquer outro local onde ocorra acúmulo de resíduos de leite.

Durante o intervalo entre as ordenhas, enquanto as vacas estão deitadas, ocorre intensa contaminação da pele dos tetos e do úbere, principalmente se o ambiente estiver altamente contaminado. A cama ou local de permanência dos animais pode abrigar elevadas cargas microbianas, podendo atingir uma contagem bacteriana de $10^{8}$ a $10^{10} \mathrm{ufc} / \mathrm{ml}$ (BRAMLEY, 1982; HOGAN et al., 1989). Nestas condições, os principais microrganismos isolados são estreptococos, estafilococos, microrganismos formadores de esporos, coliformes e outras bactérias Gram-negativas. A pele do teto das vacas antes da ordenha pode estar contaminada por microrganismos psicrotróficos, capazes de crescer em baixas temperaturas, e os termoduricos, os quais são resistentes à pasteurização (DESMASURES e GUEGUEN, 1997).

A indústria leiteira mundial atravessa um período de intensas transformações em sua estrutura, e pode-se identificar como principais tendências a diferenciação do pagamento ao produtor e o aumento nas exigências de qualidade do leite por parte das indústrias, assim como maior preocupação dos consumidores com relação à segurança alimentar (PRATA, 1998). Nesse novo cenário, os produtores precisam se adequar de forma a manter a atividade de produção de leite como uma operação rentável e eficaz. 
Recentemente a legislação sobre a produção de leite no Brasil foi alterada pelo Ministério da Agricultura, Pecuária e Abastecimento (MAPA). O antes denominado "Programa Nacional de Melhoria da Qualidade do Leite", que tinha como objetivo implementar várias mudanças na legislação brasileira no que se refere à qualidade do leite passou por consulta pública e, após algumas alterações, transformou-se na Instrução Normativa $\mathrm{n}^{\circ}$ 51. As principais mudanças que esta nova Instrução Normativa trará será a adoção de parâmetros de qualidade como a contagem bacteriana total, a contagem de células somáticas, a ausência de resíduos de antibióticos, entre outros. A adaptação dos produtores a esta nova lei será feita de forma gradual a atingir os níveis finais de requerimento em um prazo de 7 anos após a sua entrada em vigor que, no caso da contagem de bactérias, o máximo permitido será de $0,1 \times 10^{6} \mathrm{ufc} / \mathrm{ml}$ (SANTOS, 2002). Neste cenário, foi proposto realizar este trabalho com o objetivo de avaliar a influência da adoção de diferentes técnicas profiláticas de higiene e limpeza, durante o manejo de produção, na qualidade microbiológica de leite por meio da contagem de bactérias psicrotróficas.

\section{MATERIAL E MÉTODOS}

O experimento foi conduzido com o apoio do Laticínio Matilat, município de Catanduva, São Paulo. Inicialmente, foram realizadas visitas a algumas propriedades fornecedoras de leite para observar as condições higiênicas durante e após o processo de ordenha. Foram escolhidas quatro propriedades onde se constatou falhas quanto às medidas profiláticas de controle de qualidade higiênica do leite. Dessas quatro propriedades, três utilizavam ordenhadeiras mecânicas e um ordenha manual com bezerro ao pé da vaca. Para as quatro propriedades escolhidas foram realizados questionários contendo as seguintes informações: tipo de ordenha; volume de produção; água de lavagem; limpeza do estábulo; limpeza de equipamentos; limpeza de tetos; asseio do ordenhador e horário das ordenhas. Adicionalmente, foi realizado um levantamento da saúde das vacas, das técnicas de armazenagem pós-coleta e outros procedimentos de higiene.

Em cada propriedade coletaram-se cinco amostras representando as coletas (ordenhas) realizadas em períodos distintos: a primeira referenciou a amostra controle, ou seja, anterior à adoção das técnicas profiláticas e as amostras posteriores foram coletadas após a adoção das profilaxias. Em todas as propriedades, as amostragens foram realizadas diretamente do tanque de resfriamento no dia da ordenha e colocadas em frascos de plásticos estéreis, os quais foram encaminhados para o laboratório do laticínio, para análises microbiológicas de contagem total de bactérias psicrotróficas, mediante o método oficial recomendado para contagem padrão em placas com incubação a $21^{\circ} \mathrm{C}$ em Agar padrão (PCA), por 48hs (SILVA et al., 2001). seguintes:

As medidas profiláticas realizadas foram as

a) Utensílios e equipamentos - lavagem de todas as borrachas, latões, teteiras, usando bucha, detergente neutro ou escovas, cloro e água potável; os utensílios (balde, latões, peneiras, coadores, etc) foram mantidos em local limpo e protegido, livre de insetos e animais; a limpeza dos utensílios foi iniciada logo após o término da ordenha; quando possível utilizando água quente ou morna, com temperatura de aproximadamente $45^{\circ} \mathrm{C}$; trocaram-se os latões enferrujados; após a limpeza, os latões foram virados de boca para baixo e as teteiras mergulhadas em solução de água clorada por 15-20 minutos $(1,0 \mathrm{ml}$ de solução de hipoclorito de sódio, contendo $10 \%$ de cloro ativo/ para cada litro de água); foi utilizado balde semi - aberto na ordenha no caso da ordenha manual;

b) Higiene dos operadores/ordenhadores - foram adotadas práticas de higiene lavando-se as mãos e braços com sabão; uso de roupas limpas com unhas cortadas, mantendo hábitos limpos na hora da ordenha, quando possível utilizando luvas, botas de borracha e bonés; manteve-se uma postura calma para manejar os animais, sem gritar ou bater; o responsável pela ordenha não fumou, bebeu ou comeu durante a ordenha;

c) Ambiente - não foi permitida entrada de cachorros, gatos, galinhas ou outros animais no estábulo; foi realizada lavagem do piso diariamente com detergente e cloro e lavagem geral da sala de ordenha em intervalos de aproximadamente 15 dias.

d) Manejo dos animais - a ordem de ordenha foi animais sadios primeiro seguidos dos animais com mastite sub-clínica (do menor para o maior grau de infestação); foram desinfetados os conjuntos de ordenha para ordenhar os animais com colostro e por último os animais com mastite clínica; os tetos foram lavados e secos com papel toalha; foi aplicado iodo antes e depois da ordenha.

\section{RESULTADOS E DISCUSSÃO}

Algumas informações básicas contidas no questionário e coletadas nas quatro propriedades rurais são apresentadas no Quadro 1.

Ciênc. agrotec., Lavras, v. 29, n. 1, p. 216-222, jan./fev. 2005 
QUADRO 1 - Características principais das quatro propriedades rurais produtoras de leite avaliadas.

\begin{tabular}{|l|c|c|c|c|}
\hline \multirow{2}{*}{ Tipo de ordenha } & \multicolumn{4}{|c|}{ PROPRIEDADE } \\
\cline { 2 - 5 } & A & B & C & D \\
\cline { 2 - 5 } & Mecanizada & Mecanizada & Mecanizada & Manual \\
\hline Número de vacas & 40 & 42 & 55 & 38 \\
\hline Número de ordenhas/dia & duas & duas & quatro & duas \\
\hline Produção média & 360 litros/dia & 3001 litros/dia & 900litros/dia & 180litros/dia \\
\hline
\end{tabular}

Com base no questionário aplicado, constatou-se que em todas as propriedades havia falhas nos procedimentos de higiene e limpeza, bem como a ocorrência de muitos animais com mastite sub-clínica. No diagnóstico inicial, foi constatado na propriedade "A" o uso de latões de armazenagem enferrujados e que as mangueiras de ligação para o tanque de resfriamento eram lavadas somente uma vez por mês. Porém, no teste de mastite subclínica apenas uma vaca apresentou resultado positivo. $\mathrm{Na}$ propriedade " $\mathrm{B}$ " foram observadas muitas moscas e muita poeira na sala de ordenha. Havia latões enferrujados e sujos, mangueiras velhas e sujas, peneiras em mal estado. Foram realizados testes para mastite sub-clínica e aproximadamente 10 vacas apresentaram resultado positivo.

Ainda com base no questionário, na propriedade "C" o teste da mastite sub-clínica era feito uma vez por mês por veterinário, porém, não foi relatada a ocorrência de resultados positivos. Constatou-se nessa propriedade que eram executadas todas as práticas de limpeza dos utensílios e dos equipamentos e higienização dos tetos das vacas. Porém, em função da capacidade do tanque de resfriamento ser limitado, aproximadamente 500 litros de leite eram armazenados em latões e colocados em câmara fria.

Foi observado na propriedade " $D$ " que muitas vacas apresentaram mastite sub-clínica e que o teste para este diagnóstico não era realizado pelo produtor. Foram observadas também verrugas nos tetos das vacas ordenhadas.

Em todas as propriedades a água utilizada era de poço artesiano e os ordenhadores não utilizavam qualquer tipo de uniforme especial para a função. Com exceção da propriedade "C", as práticas de higienização dos tetos, da ordenhadeira e dos utensílios eram realizadas de forma ineficiente e sem critérios.

Pelo resultado do questionário observou-se mostrou também que a propriedade " $D$ " era a que aplicava com menor rigor e com inadimplência as técnicas profiláticas, porém, foi a que apresentou o segundo menor índice de contagem bacteriana (Figura 4), seguida da propriedade "C" (Figura 3). Isso demonstra uma possível falha no acompanhamento técnico, por parte das propriedades "A" $\mathrm{e}$ " $\mathrm{B}$ ", no que diz respeito às aplicações das normas e técnicas preventivas de higiene pelos funcionários, que efetivamente são aqueles que operam o sistema de produção.

$\mathrm{Na}$ avaliação das técnicas profiláticas de higiene adotadas, observou-se uma redução significativa na contagem de microrganismos psicrotróficos a partir do segundo período de coleta de leite em todas as propriedades (Figuras 1, 2, 3 e 4). Ao se comparar as qualidades microbiológicas do leite entre as propriedades avaliadas, observa-se que a propriedade "C" foi a que apresentou melhor qualidade pela contagem inicial de bactérias (Figura 3), com índices entre 0,16 e $0,18 \times 10^{6}$ UFC/ml. Foi também esta, a propriedade rural com maior produtividade média diária de leite, ao redor de 900 l/dia e, também, a que aplicava com maior critério e eficiência as práticas preventivas de higiene e limpeza, conforme o resultado do questionário. Apesar disso, mesmo aplicando-se com mais rigor e de forma planejada as técnicas profiláticas, como foi o intuito deste trabalho, foi possível diminuir mais ainda o índice de contagem bacteriana do leite nessa propriedade. Isso mostra a importância da adoção de práticas higiênicas durante a ordenha das vacas como medida preventiva contra contaminações microbianas do leite, para a diminuição da sua carga bacteriana inicial.

Por outro lado, outro aspecto igualmente importante leva em conta que tais práticas, ao serem adotadas, também contribuem para diminuir a possibilidade de infecções mamárias dos animais. De acordo com Santos (2002), além dos efeitos positivos sobre a qualidade do leite, os procedimentos de preparação do úbere antes da ordenha têm efeito importante sobre a ocorrência de novas infecções intramamárias (mastite), visto que o risco

Ciênc. agrotec., Lavras, v. 29, n. 1, p. 216-222, jan./fev. 2005 
destas novas infecções está diretamente associado com a intensidade de contaminação da extremidade dos tetos. Desta forma, um dos objetivos da desinfecção dos tetos antes da ordenha é reduzir a contaminação da extremidade dos tetos e, conseqüentemente, reduzir o risco de novas infecções.

Na propriedade B (Figura 2), somente a partir do terceiro dia de coleta de leite, a contagem de microrga- nismo reduziu significativamente. Isto ocorreu, provavelmente porque na primeira coleta o produtor não havia iniciado as técnicas higiênicas por duvidar que as mesmas seriam eficazes, porém, na segunda coleta ele as adotou, mas não com rigor, o que resultou em um decréscimo na contaminação do leite.

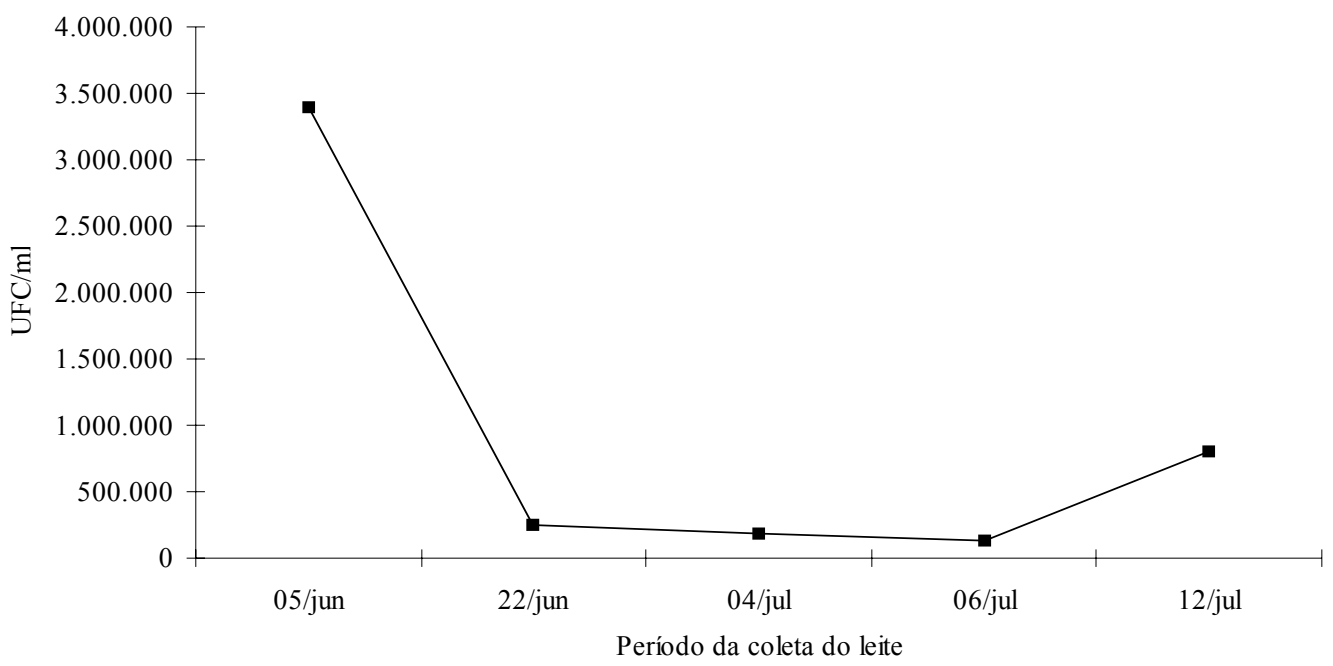

FIGURA 1 - Contagem total de bactérias psicrotróficas do leite obtido na propriedade A, com ordenha mecanizada.

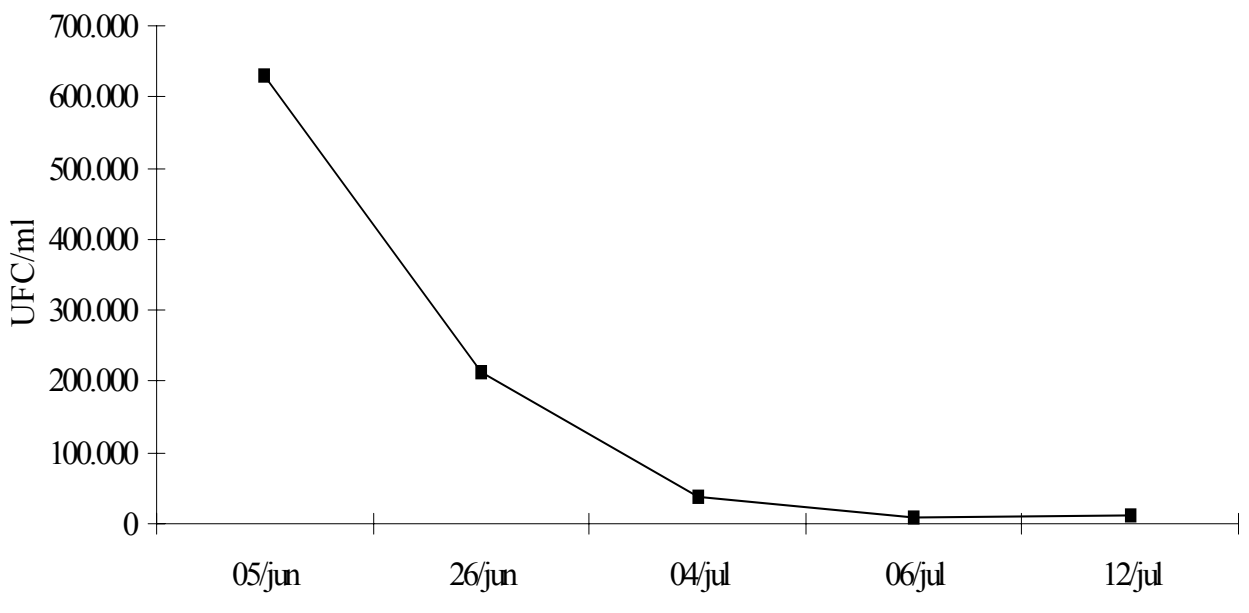

Período da coleta do leite

FIGURA 2 - Contagem total de bactérias psicrotróficas do leite obtido na propriedade B, com ordenha mecanizada. 


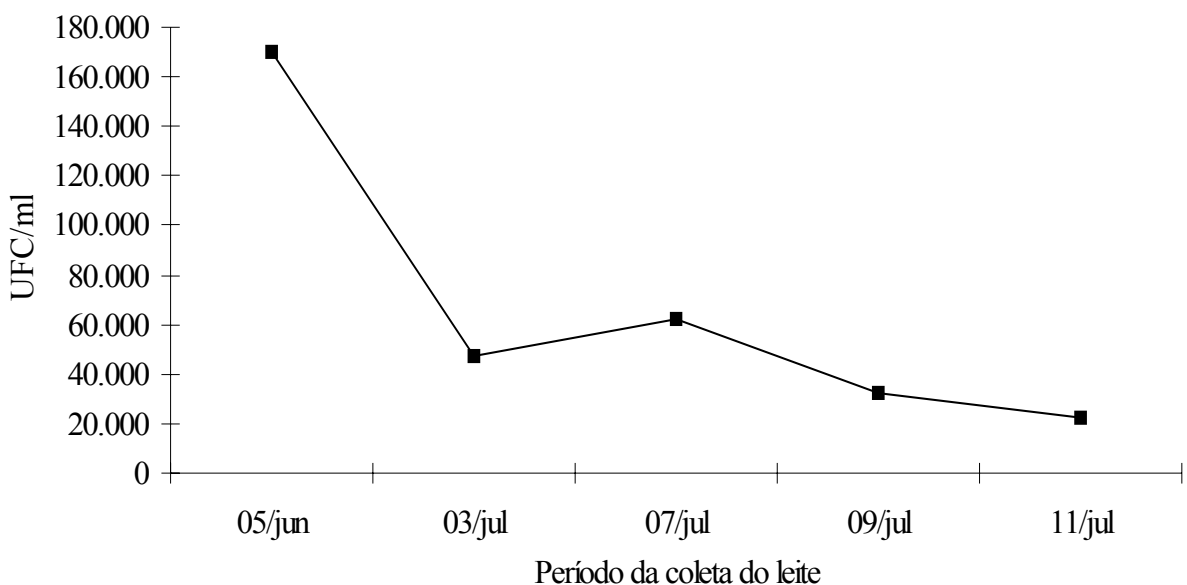

FIGURA 3 - Contagem total de bactérias psicrotróficas do leite obtido na propriedade $\mathrm{C}$, com ordenha mecanizada.

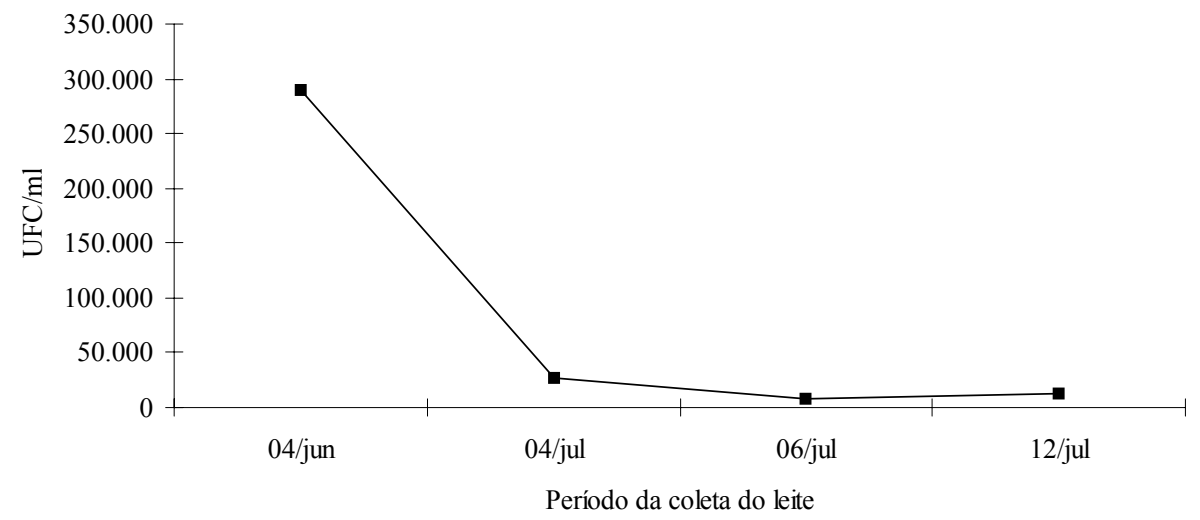

FIGURA 4 - Contagem total de bactérias psicrotróficas do leite obtido na propriedade D, em ordenha manual com bezerro ao pé.

$\mathrm{Na}$ caracterização das propriedades, com base em seus índices de contaminação bacteriana do leite, uma das três propriedades com ordenha mecânica, apresentou resultado inicial de contaminação relativamente elevado de $3,5 \times 10^{6} \mathrm{UFC} / \mathrm{ml}$ (Figura 1). Contagem essa muito maior do que o observado na propriedade com ordenha manual rudimentar (Figura 4), indicando que o nível tecnológico utilizado na ordenha não implica, necessariamente, em um leite com melhor qualidade microbiológica e sim em mais um item a ser considerado como possível agente de contaminação bacteriana. Deve-se considerar que o equipamento de ordenha é uma fonte importante de contaminação do leite e os procedimentos de limpeza e higienização, nesse componen- te, podem influenciar diretamente no índice de contaminação microbiana do leite. Segundo Santos e Fonseca (2001), microrganismos termodúricos podem se aderir nas superfícies do equipamento de ordenha como: mangueiras e conexões e resistir ao uso de água quente durante a limpeza. Caso sobrem resíduos de leite, estes microrganismos sobreviventes podem se multiplicar de forma lenta, aumentando assim a contaminação. As mangueiras e outras partes de borracha que não são trocadas freqüentemente podem apresentar rachaduras e fissuras pelo uso prolongado, onde ocorrem acúmulos de resíduos de leite e intensa multiplicação microbiana ao longo do tempo, principalmente de psicrotróficos, que afetam diretamente a contagem bacteriana total do leite.

Ciênc. agrotec., Lavras, v. 29, n. 1, p. 216-222, jan./fev. 2005 
Esses fatos podem ser facilmente aceitos pelo resultado inicial de contaminação observado na propriedade com uso de ordenha manual (Figura 4) que apresentou índice de contaminação bem inferior, ao redor de $0,3 \times 10^{6}$.

Ficou claro que o produtor ainda parece desconhecer os princípios básicos sobre higiene do leite, notadamente no que diz respeito à própria definição sobre contaminação bacteriana e suas implicações na qualidade do leite e na saúde mamária do rebanho. Estabelece-se, pelos fatos, o desafio maior de desenvolver programas de treinamento e educação para os produtores rurais por parte dos órgãos competentes. A ausência de tais programas, somada às medidas da nova Instrução Normativa 51, que prevê níveis máximos de contagem bacteriana, pode acarretar em um grande número de produtores que não irão atender aos requisitos mínimos de qualidade do leite.

\section{CONCLUSÃO}

Conclui-se que em todas as propriedades, após a adoção das técnicas profiláticas estudadas durante a etapa produtiva, ocorreram diminuições significativas na contagem total de bactérias psicrotróficas, comprovando a importância de práticas de higiene e limpeza sobre a qualidade microbiológica do leite.

\section{REFERÊNCIAS BIBLIOGRÁFICAS}

BRAMLEY, A. J. Sources of Streptococcus uberis in the dairy herd I: isolation from bovine feces and from straw bedding of cattle. Journal of Dairy Research, Cambridge, v. 49, p. 369, 1982.

CASTBERG, H. G. Lipase activity. International Dairy Federation Bulletin, Brussels, v. 271, p. 18-20, 1992.

COUSIN, M. A. Presence and activity psychrotrophic microorganisms in milk and dairy products. Journal of Food Protection, Des Moines, v. 45, p. 172, 1982.

COUSIN, M. A.; BRAMLEY, A. J. The microbiology of raw milk. In: ROBINSON, R. K. Dairy microbiology. New York: Applied Science, 1981. v. 1, p. 119-163.
DEMASURES, N.; GUEGUEN, M. Monitoring the microbiology of high quality milk by monthly sampling over 2 years. Journal of Dairy Research, Cambridge, v. 64, p. 271-280, 1997.

DOWNEY, W. K. Review of the progress of dairy science: flavour impairment from pre and postmanufacture lipolysis in milk and dairy products. Journal Dairy Research, Cambridge, v. 47, p. 237252,1980 .

FONSECA, L. F. L. Qualidade do leite e sua relação com equipamento de ordenha e sistema de resfriamento. In: SIMPÓSIO INTERNACIONAL SOBRE QUALIDADE DO LEITE, 1., 1998, Curitiba, PR. Anais... Curitiba: [s.n.], 1998. p. 54-56.

HOGAN, J. S. et al. Bacterial counts in bedding materials used on nine commercial dairies. Journal Dairy Science, Champaign, v. 72, p. 250, 1989.

MA, Y. et al. Effects of somatic cell count on quality and shelf-life of pasteurized fluid milk. Journal Dairy Science, Champaign, v. 83, p. 264-274, 2000.

PRATA, L. F. Fundamentos de ciência do leite. São Paulo: Unesp, 1998. 119 p.

SANTOS, M. V. Efeito da mastite sobre a qualidade do leite e dos derivados lácteos. In: CONGRESSO PANAMERICANO DE QUALIDADE DO LEITE E CONTROLE DE MASTITE, 2., 2002, Ribeirão Preto, SP. Anais... Disponível em: $<$ www.milkpoint.com.br/mn/radarestecnicos $>$. Acesso em: 26 mar. 2003.

SANTOS, M. V.; FONSECA, L. F. L. Importância e efeito de bactérias psicrotróficas sobre a qualidade do leite. Revista Higiene Alimentar, São Paulo, v. 15, n. 82 , p. 13-19, 2001.

SILVA, N.; JUNQUEIRA, V. C. A.; SILVEIRA, N. F. A. Manual de métodos de análise microbiológica de alimentos. São Paulo: Varela, 2001. 317 p. 